\title{
Patient-specific electronic decision support reduces prescription of excessive doses
}

\author{
H M Seidling, ${ }^{1,2}$ S P W Schmitt, ${ }^{1}$ T Bruckner, ${ }^{3} \mathrm{~J}$ Kaltschmidt, ${ }^{1}$ M G Pruszydlo, ${ }^{1}$ \\ C Senger, ${ }^{1}$ T Bertsche, ${ }^{1,2}$ I Walter-Sack, ${ }^{1}$ W E Haefeli ${ }^{1,2}$
}

'Department of Internal Medicine VI, Clinical Pharmacology and Pharmacoepidemiology, University of Heidelberg, Heidelberg, Germany ${ }^{2}$ Cooperation Unit Clinical Pharmacy, University of Heidelberg, Heidelberg, Germany

${ }^{3}$ Institute of Medical Biometry and Informatics, University of Heidelberg, Heidelberg, Germany

\section{Correspondence to}

Professor Walter E Haefeli, Department of Internal Medicine VI, Clinical Pharmacology and Pharmacoepidemiology, University of Heidelberg, Im Neuenheimer Feld 410, Heidelberg 69120, Germany: walter.emil.haefeli@ med.uni-heidelberg.de

Accepted 31 August 2009 Published Online First 27 April 2010

\begin{abstract}
Objectives Prescription of excessive doses is the most common prescription error, provoking dose-dependent adverse drug reactions. Clinical decision support systems (CDSS) can prevent prescription errors especially when mainly clinically relevant warnings are issued. We have built and evaluated a CDSS providing upper dose limits personalised to individual patient characteristics thus guaranteeing for specific warnings.
\end{abstract}

Methods For 170 compounds, detailed information on upper dose limits (according to the drug label) was compiled. A comprehensive software-algorithm extracted relevant patient information from the electronic chart (eg, age, renal function, comedication). The CDSS was integrated into the local prescribing platform for outpatients and patients at discharge, providing immediate dosage feedback. Its impact was evaluated in a 90-day intervention study (phase 1: baseline; phase 2: intervention). Outcome measures were frequency of excessive doses before and after intervention considering potential induction of new medication errors. Moreover, predictors for alert adherence were analysed. Results In phase 1, 552 of 12197 (4.5\%) prescriptions exceeded upper dose limits. In phase 2, initially 559 warnings were triggered $(4.8 \%, p=0.37)$. Physicians were responsive to one in four warnings mostly adjusting dosages. Thus, the final prescription rate of excessive doses was reduced to $3.6 \%$, with $20 \%$ less excessive doses compared with baseline $(p<0.001)$. No new manifest prescription errors were induced. Physicians' alert adherence correlated with patients' age, prescribed drug class, and reason for the alert.

Conclusion During the 90-day study, implementation of a highly specific algorithm-based CDSS substantially improved prescribing quality with a high acceptance rate compared with previous studies.

Medication errors are critical flaws challenging safe drug treatment. ${ }^{1}$ They occur at all stages of pharmacotherapy, but the prescription process is particularly error-prone, accounting for more than $50 \%$ of errors. ${ }^{2}$ Most prescription errors concern the selection of excessive doses, thus promoting dosedependent adverse drug reactions. ${ }^{3}$ Unintentional prescription of excessive doses may result from calculation errors, ${ }^{4}$ but most often, individual patient characteristics requiring dosage individualisation are neglected. Modulators of dosage requirements include patients' comorbidities (eg, liver or renal dysfunction ${ }^{5} 6$ ), comedication, ${ }^{7}$ age-associated pharmacodynamic changes, ${ }^{8}$ or genetic predisposition. ${ }^{9}$ To furnish the physician during the prescription process with relevant information, clinical decision support systems (CDSS) have proven successful. ${ }^{10}$ Integrated into computerised physician order entry (CPOE) systems and linked with clinical records, software algorithms allow for patientspecific recommendations. Indeed, CDSS have supported drug dosing for oral anticoagulants, ${ }^{11}$ antibiotics $^{12}$ or drugs requiring therapeutic drug monitoring (eg, theophylline ${ }^{13}$ ). Moreover, electronic dosage recommendations have been generated for specific patient populations with particular dosage requirements including elderly, ${ }^{14}$ paediatric, ${ }^{15}$ and kidney failure patients. ${ }^{16}$ However, no CDSS has been developed and evaluated that focusses on prevention of overdoses for a large number of drugs covering relevant diseases of diverse patient populations.

We thus developed a CDSS that adjusted upper dose limits to patient characteristics and comedication and provided immediate feedback in a CPOE. We then prospectively assessed its impact on prescription quality.

\section{METHODS \\ Development of an algorithm determining individualised upper dose limits}

A team of pharmacists, physicians and computer scientists built an algorithm for the definition of individual upper dose limits. Standard maximum recommended therapeutic dose (MRTD) values were defined as highest maintenance dose administered to ambulatory patients. ${ }^{17}$ For individualisation of these values, drug regulatory authorities demand dosage recommendations considering: (1) age, (2) renal function, (3) liver disease, (4) comedication, (5) indication of the drug and (6) administration of loading doses. ${ }^{18}$ Thus, detailed dosage information was compiled by screening the summary of product characteristics (SPC) of the originator brand. Included were frequently prescribed active ingredients that accounted for $>75 \%$ of all prescriptions of our hospital in 2007 and, additionally, all compounds classified as critical dose drugs by the Canadian Health Organisation. ${ }^{19}$ Hence, for 170 compounds, standard MRTD values for specific routes of administration $\left(M R T D_{R O A}\right)$ were extracted, including lower and higher MRTDs where applicable (table 1).

Because SPC information for patients with renal impairment was often missing and in many cases had considerable flaws, ${ }^{20}$ we calculated dose modifications using a well-established standard pharmacokinetic approach: for active ingredients of which at least $50 \%$ is eliminated unchanged by the kidneys $\left(Q_{0}\right.$ (bioavailable fraction of a drug eliminated extrarenally) $<0.5 ; n=23$ ) MRTD values were 
Table 1 Definition of specific maximum recommended therapeutic dose (MRTD) values

\begin{tabular}{|c|c|c|}
\hline $\begin{array}{l}\text { Type of MRTD } \\
\text { value }\end{array}$ & Characteristic of MRTD value & $\begin{array}{l}\text { Number of extracted } \\
\text { values for the study }\end{array}$ \\
\hline $\mathrm{MRTD}_{\mathrm{ROA}}$ & Standard MRTD value referring to a drug with a specific route of administration and dosage form & 170 \\
\hline MRTD $_{\text {Age }}$ & Lower MRTD value applying to elderly patients (patient's age is automatically extracted from the patient's electronic chart) & 17 \\
\hline MRTD & $\begin{array}{l}\text { Lower MRTD value applying to patients with impaired liver function (if relevant, the physician was asked to specify the } \\
\text { patient's liver function) }\end{array}$ & 13 \\
\hline MRTD DDI_up & $\begin{array}{l}\text { Higher MRTD value due to interacting comedication reducing drug exposure (concurrently prescribed drugs are automatically } \\
\text { extracted from the medication regimen) }\end{array}$ & 4 \\
\hline MRTD $_{\text {Timepoint }}$ & $\begin{array}{l}\text { Higher MRTD value applying to substances given at higher dosages at the beginning of therapy (if relevant, the physician was } \\
\text { asked to specify whether he intended to administer a loading dose) }\end{array}$ & 25 \\
\hline MRTD $_{\text {Kidney }}$ & $\begin{array}{l}\text { Higher MRTD value applying to substances that require dosage increase in case of renal impairment (laboratory values } \\
\text { determining renal function were automatically extracted from the patient's electronic chart) }\end{array}$ & 3 \\
\hline
\end{tabular}

ICD-10, International Statistical Classification of Diseases and Related Health Problems - 10th Revision.

adjusted according to equation $1,{ }^{21}$ where $Q$ is the individual elimination capacity and the glomerular filtration rate (GFR).

$Q=Q_{0}+\left(1-Q_{0}\right) \times \frac{G F R}{100}$

For estimation of the GFR, we used Dettli's modification of the Cockcroft-Gault equation ${ }^{21}$ as one of the well-established creatinine-based equations to estimate kidney function ( $k$ is 0.9 for females and 1.1 for males) (equation 2):

$G F R=\frac{(150-\operatorname{age}(y)) \times \text { weight }(\mathrm{kg}) \times k}{\text { serum creatinine }(\mu \mathrm{mol})}$

The CDSS was integrated into our CPOE (AiDKlinik) linking medication regimens to clinical records, thus allowing for determination of $Q$ and individual adjustment of MRTD to the patient's conditions $\left(\mathrm{MRTD}_{\text {final }}\right)$. No information was available reliably identifying patients with impaired liver function or receiving loading doses. Therefore, whenever the respective MRTD value would apply as MRTD final and the prescribed dose would exceed this MRTD value, the physician was asked for details. In a final step, $\mathrm{MRTD}_{\text {final }}$ was individualised to renal function (iMRTD) (equation 3).

$i M R T D=M R T D_{\text {final }} \times Q$

The overall strategy was therefore to (1) select the lowest MRTD value applicable to an individual patient and (2) adjust this value to individual renal elimination capacity (figure 1).

\section{Implementation of iMRTD values into the CPOE}

Information on iMRTD values was visualised by an informative text and a colour-coded icon next to each prescription indicating whether

1. no dosage information was available in the CDSS for the respective drug (grey), or

2. an appropriate (green), or

3. excessive dose (red) was prescribed, or

4. relevant information on the patient's condition or dosage regimen was lacking (purple).

A prescription was classified as overdosed if the prescribed daily dose (PDD) exceeded iMRTD. In order to avoid overalerting, we allowed a dose calculation range of $+30 \%$ (slightly above standard bioequivalence ranges ${ }^{22}$ ). Moreover, we also considered plasma or blood concentrations (measured within the last 7 days) of narrow therapeutic index drugs $(n=40)$. These drugs would only be classified as overdosed if drug concentrations were in excess of the respective therapeutic range. When a patient was classified as overdosed, physicians were invited to modify the dosage regimen or to specify their reasons for disregarding the alert.

\section{Study design}

After approval by the responsible ethics committee, we conducted a prospective, open, monocentric study with two sequential phases (phase 1: baseline assessment; phase 2: intervention) at a tertiary care university hospital between July and October 2008 (figure 2). We evaluated electronic prescriptions as included in discharge letters or printed onto prescription forms. Whereas in phase 1 no dosage information was given, immediate feedback on dosage was provided in phase 2 .

To evaluate the benefit of the intervention, the frequency of inappropriate dosage regimens before and after the intervention was compared. Moreover, physicians' behaviour in response to alerts was assessed. Factors potentially influencing physicians' decision to override the alert were analysed by univariate and (if reaching statistical significance) multivariate analyses considering (1) prescribed compound, (2) substantial dose-dependent toxicity, (3) reason for the alert, (4) magnitude of overdosage, (5) number of concurrent drugs, (6) prescription procedure (prescription form/discharge letter), (7) timing of the prescription in the course of the study, (8) type of MRTD value $\left(M_{R T D}{ }_{R O A}\right.$ or iMRTD), (9) age and (10) gender. Therefore, reactions were dichotomously classified as "reacted" and "did not react". Because CDSS themselves can trigger prescription errors, ${ }^{23}$ we assessed how often in response to the alert

1. physicians removed the dosage regimen or

2. a drug completely from the medication regimen without defining an alternative drug (potential underuse), and

3. the modified dosage was below therapeutic ranges (potential underdosing).

\section{Inclusion and exclusion criteria}

We analysed all medication regimens written with the CPOE and stored in the system. For comparison of baseline and intervention phase, electronically prescribed drugs (EPD) fulfilling the following criteria were included:

1. prescription of a drug with systemic availability,

2. issued in a hospital department using the CPOE during the whole study period

3. with MRTD information in our database. 
Figure 1 Algorithm describing the selection of the individual MRTD value (iMRTD) and implementation of immediate feedback on prescribed dosages in the electronic prescription platform.

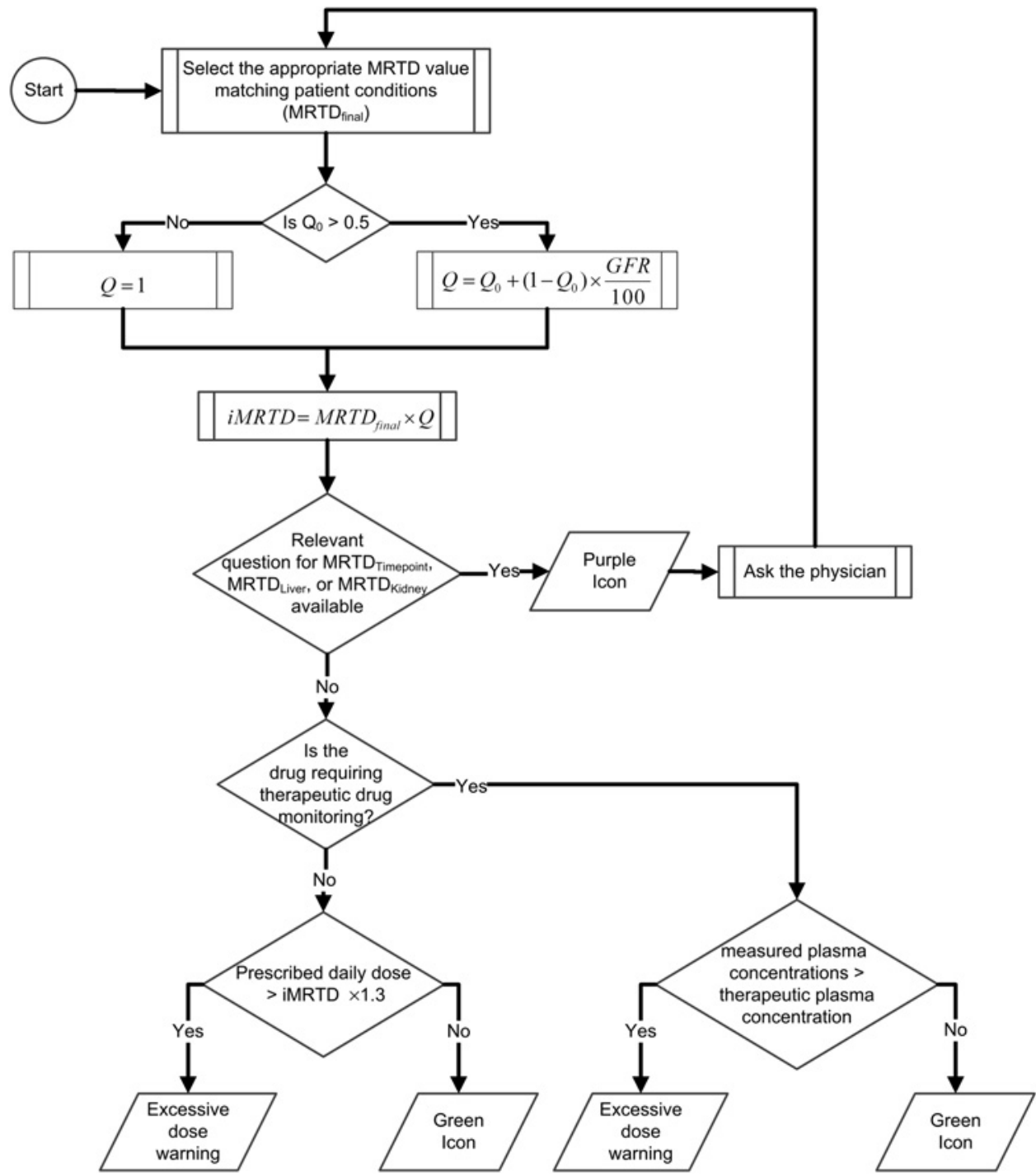

\section{Statistical design}

Under the conservative assumption that $2 \%^{3} 17$ of all EPD exceed upper dose limits and the intervention reduces inappropriate dosage regimens by $25 \%$, evaluation of 10795 EPD in each observation period was necessary to reach statistical significance
( $\chi^{2}$ analysis, $\alpha=0.05$, power $=0.8$ ). The respective numbers of prescriptions were reached after 45 days in each study phase. Results are reported as means (SD) or proportions. Nominal variables were analysed with $\chi^{2}$ test or Fisher's exact $t$ test), ordinal and metric data with Mann-Whitney $U$ test or with

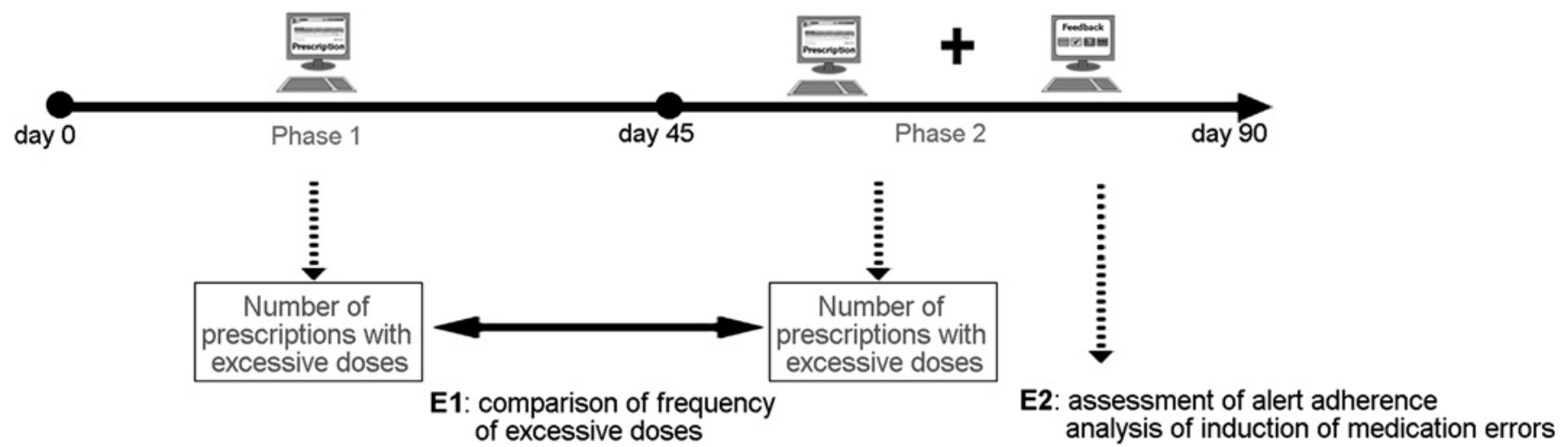

Figure 2 Study design for prospective evaluation of a clinical decision support system providing immediate feedback on prescribed dosages. E1, primary endpoint; E2, secondary endpoint. 
Kruskal-Wallis test, if $n>2$ groups were compared. Factors influencing physicians' behaviour were analysed with a binary logistic regression model. All analyses were performed with SPSS for Windows V.16.0, considering p values $<0.05$ significant.

\section{RESULTS}

\section{Descriptive analysis}

Ninety-five hospital wards or clinics issued prescriptions in both study phases, most of them belonging to internal medicine. In phase 1, 21333 EPD matched the inclusion criteria and 21111 in phase 2. These prescriptions were issued for 8892 patients of whom 1086 received prescriptions in both study phases. Accordingly, in phase 1, 5030 patients (53.4\% female) were included in the analysis, with a mean (SD) age of 55.9 years (16). In phase 2, 4948 patients were included (mean (SD) age of 55.9 years (15.9), 52.6\% female). In both study phases, for nearly half of the EPD physicians had not defined a dosage regimen thus precluding dosage evaluation (figures 3 and 4). EPD without dosage regimen referred to drug classes requiring frequent modification (eg, oral anticoagulants) or given as needed (eg, metoclopramide) and most often concerned prescriptions to be printed onto prescription forms.

In phase 1 (figure 3), 552 prescriptions were classified as overdosed with PDD > iMRTD (4.5\%). In phase 2, 559 prescriptions were initially classified as overdosed (4.8\%). This rate was similar to phase $1(\mathrm{p}=0.37)$. Physicians responded to 134 alerts (24\%), most often by dosage adjustment, and the number of finally prescribed excessive doses decreased to $425 \mathrm{EPD}$ $(3.6 \%)$ (figure 4$)$. Thus, the final prescription rate of excessive doses was significantly reduced by $20 \%$ compared with phase 1 $(p<0.001)$. This effect was even more pronounced in medication regimens for prescription forms (reduction by 48\%, $\mathrm{p}<0.001$ ) (table 2). In 54 of the 425 cases, where physicians stuck to the original dosage regimen, they specified a reason for the appropriateness of the prescribed dosage (12\%), most often claiming that the dosage was considered clinically appropriate $(n=47)$.

\section{Predictors for physicians' alert adherence}

Physicians' reaction to all 559 EPD of phase 2 triggering an overdose warning was analysed. All factors reaching statistical significance in univariate and multivariate analyses are summarised in table 3. Alert adherence was independent of patient gender, type of prescription procedure, and timing of the prescription in the study. Substantial dose-dependent toxicity tended to enhance physicians' willingness to respond ( $p=0.102$, Fisher's exact $t$ test); however, there were only few critical dose drugs included. The magnitude of overdosage influenced the type of reaction: if iMRTD values were surpassed only slightly, the physician would rather stick to the original dosage regimen but enter a reason for disregarding the alert. However, if PDD substantially exceeded iMRTD, dosage was rather adjusted. Physicians tended to be more responsive to alerts triggered by standard, well-known MRTD $_{\text {ROA values }}(\mathrm{p}=0.054)$.

\section{Induction of medication errors}

During phase 2, 15 overdose warnings were triggered, after which the concerned active ingredient was removed from the medication regimen. However, in 14 cases, physicians replaced the drug by an appropriate alternative (eg, changing from highdosed simvastatin to fluvastatin in a patient on cyclosporine). In one case, the physician did not prescribe an alternative active ingredient but specified in the corresponding discharge letter that therapy with this active ingredient should be stopped.
Moreover, physicians temporarily stopped four antihypertensive drugs in response to an alert. Those treatment breaks were either justified (eg, hypotensive state) or treatment was replaced by an appropriate pharmacotherapeutic alternative. In response to the overdose alert, physicians removed dosage regimens in eight cases, leaving the intended dosage regimen uncertain. When reducing the dosage in response to the alert below the iMRTD value, physicians chose dosages within therapeutic ranges in 94 of 97 cases. However, in three patients, comorbidity would also have justified the previously intended dosage.

\section{DISCUSSION}

During the study, the presented CDSS reduced prescription of excessive doses by $20 \%$ compared with the control phase. This response rate outreaches previous findings, where physicians responded only to one in ten overdose alerts ${ }^{24}$ and is only surpassed by a study where each alert had to be acknowledged to complete the prescription. ${ }^{25}$ In this earlier study, every second alert was still overridden. The high acceptance of the CDSS in our setting may have been promoted by two main features, which are also the characteristics of successful implementation $^{26}$ : (1) The CDSS was smoothly integrated in the regular prescription process with minimal user interaction and (2) provided immediate, patient-specific warnings. (3) High specificity was ensured by an algorithm calculating individual upper dose limits considering eight different patient characteristics. In comparison, standard MRTD values would have had a low sensitivity (62\%), missing one in three prescriptions with excessive doses, while on the other hand producing overalerting.

In previous studies, alert adherence often correlated with warnings estimated as clinically relevant. In contrast, we assessed specific predictors and found that physicians' alert adherence correlated with patient age, characteristics of the prescribed compound, and erroneous redundant prescriptions of the same active ingredient. In case of concurrent prescription of multiple drugs, physicians tended to override the alert,

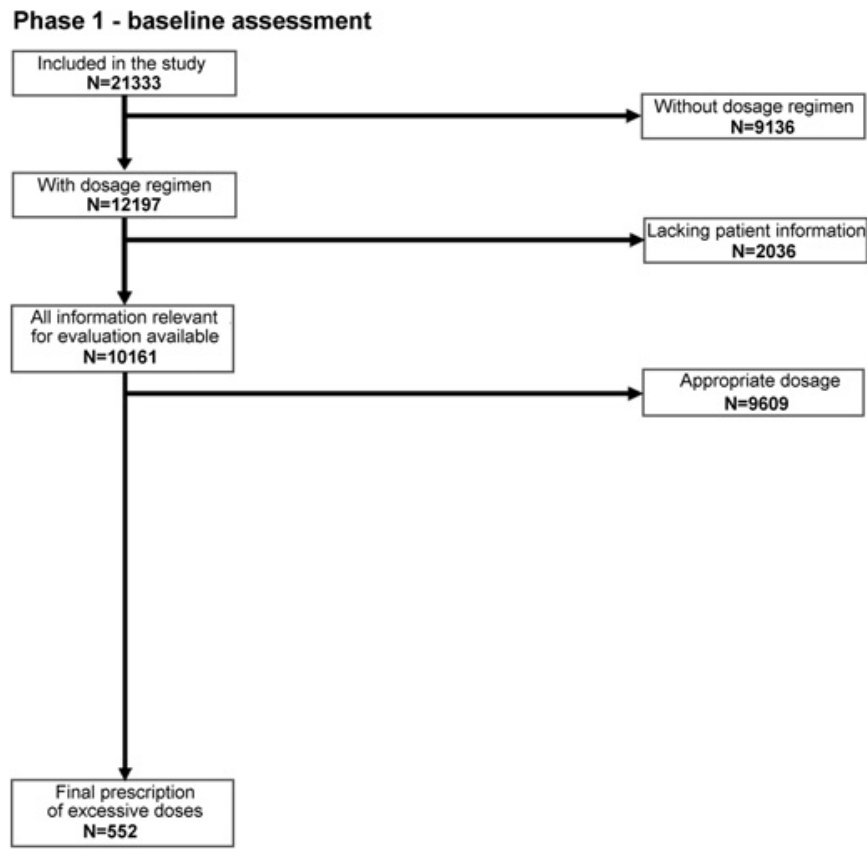

Figure 3 Flow chart of electronically prescribed drugs in baseline assessment. 
Figure 4 Flow chart of electronically prescribed drugs in the intervention phase. Dotted boxes indicate warnings or requests to which the physician potentially reacted.

\section{Phase 2 - intervention phase}

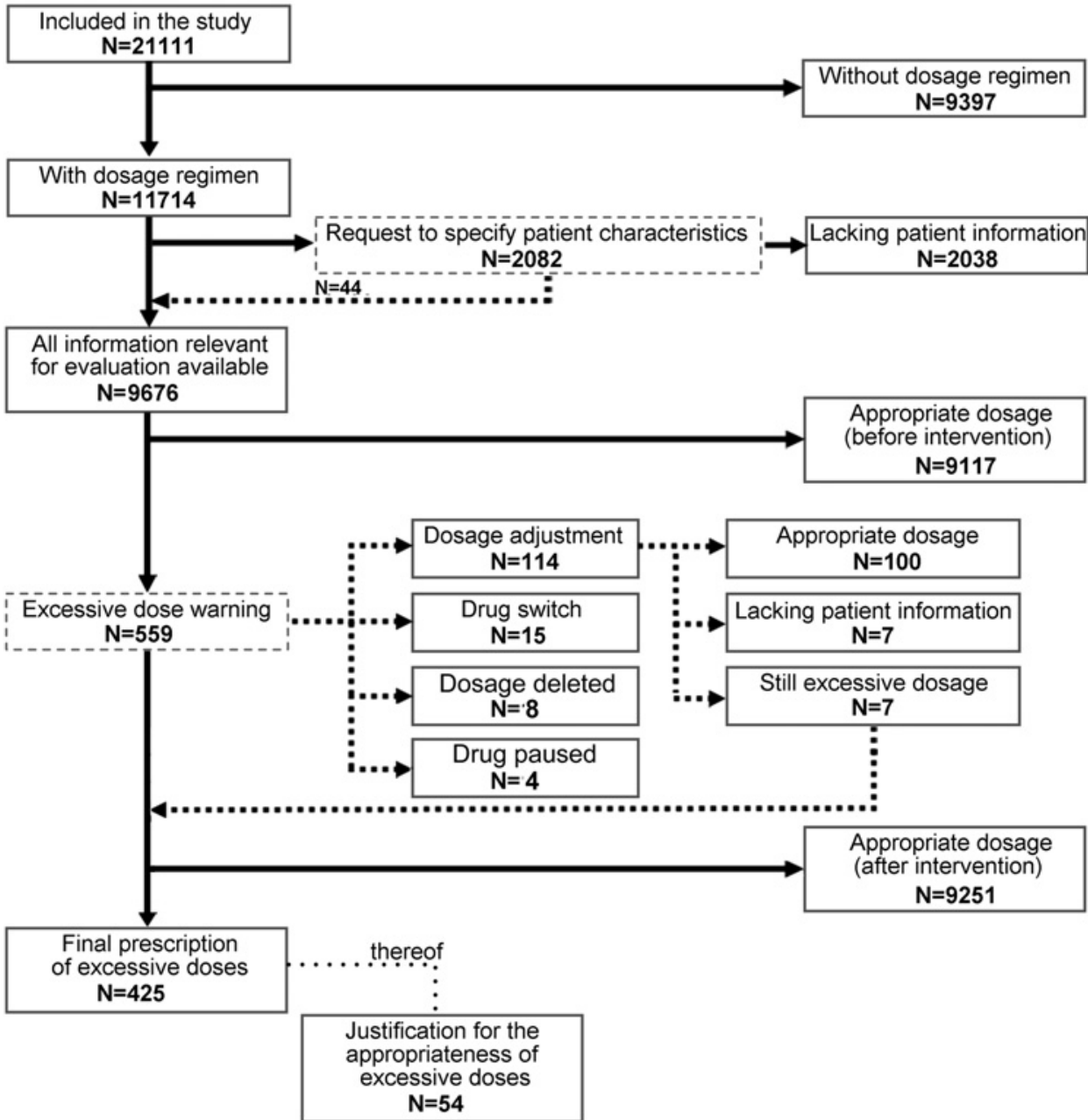

which might reflect alert-fatigue triggered by information overload rather than poor signal-to-noise ratio. ${ }^{27}$ Because adverse drug reactions are more frequent in patients on multiple drugs, ${ }^{28}$ appropriate prescribing is particularly important in this population. It is, therefore, crucial to identify patients at higher risk and prohibit easy overriding of alerts in this subgroup.

For quality control of the system, modified medication regimens were reviewed for potentially inappropriate dosages, and no new manifest prescription errors were found. However, our findings suggest that not all therapeutic groups are suitable for algorithm-based calculation of upper dose limits without further adaptation of the system. For instance, loop diuretics require a dosage increase in renal insufficiency.
Although the algorithm incorporated higher MRTD values in these cases, dosages were increased stepwise as specified in the SPC instead of gradually. Thus, dosage adjustment considering clinical effects will obviously differ from upper dose limits, which are bound to distinct GFR values. The same applies to glucocorticoids. Indeed, in this drug class, physicians often stuck to the original dosage regimen without specifying a reason for disregarding the alert. Moreover, we found that physicians specified dosage regimen only in slightly more than half of all issued prescriptions, thus precluding dosage evaluation. The omission of defined dosage schedules might be a risk factor for medication errors and should, therefore, be minimised. Measures to increase physicians' willingness to specify dosage regimens may include suggestion of standard

Table 2 Number of prescriptions classified as appropriate, overdosed, or lacking specific patient information at the end of control and intervention phase

\begin{tabular}{|c|c|c|c|c|c|c|c|c|c|}
\hline & \multicolumn{3}{|l|}{ Discharge letter } & \multicolumn{3}{|c|}{ Prescription form } & \multicolumn{3}{|l|}{ All } \\
\hline & $\begin{array}{l}\text { Control } \\
\text { phase }\end{array}$ & $\begin{array}{l}\text { Intervention } \\
\text { phase }\end{array}$ & $\begin{array}{l}p \\
\text { Value }\end{array}$ & $\begin{array}{l}\text { Control } \\
\text { phase }\end{array}$ & $\begin{array}{l}\text { Intervention } \\
\text { phase }\end{array}$ & $\begin{array}{l}\mathbf{p} \\
\text { Value }\end{array}$ & $\begin{array}{l}\text { Control } \\
\text { phase }\end{array}$ & $\begin{array}{l}\text { Intervention } \\
\text { phase }\end{array}$ & $\begin{array}{l}\mathbf{p} \\
\text { Value }\end{array}$ \\
\hline With dosage regimen & $10047(100 \%)$ & $9638(100 \%)$ & & $2150(100 \%)$ & $2076(100 \%)$ & & $12197(100 \%)$ & $11714(100 \%)$ & \\
\hline Lacking specific information & $1599(15.9 \%)$ & $1586(16.4 \%)$ & & $437(20.3 \%)$ & $452(21.8 \%)$ & & $2036(16.7 \%)$ & $2038(17.4 \%)$ & \\
\hline Appropriate dosage & $7999(79.6 \%)$ & $7679(79.7 \%)$ & & $1610(74.9 \%)$ & $1572(75.7 \%)$ & & $9609(78.8 \%)$ & $9251(79 \%)$ & \\
\hline Dosage in excess of individual upper dose limits & $449(4.5 \%)$ & $373(3.9 \%)$ & 0.036 & $103(4.8 \%)$ & $52(2.5 \%)$ & $<0.001$ & $552(4.5 \%)$ & $425(3.6 \%)$ & $<0.001$ \\
\hline
\end{tabular}

Results are stratified for the prescription procedure. 
Table 3 Univariate and multivariate analysis of predictors for physicians' adherence to the 559 overdose alerts issued in the 45-day intervention phase.

\begin{tabular}{|c|c|c|c|c|}
\hline \multirow[b]{2}{*}{ Criteria } & \multirow[b]{2}{*}{ Specification } & \multirow{2}{*}{$\begin{array}{l}\text { Univariate } \\
\text { p Value }\end{array}$} & \multicolumn{2}{|c|}{ Multivariate } \\
\hline & & & p Value & $\beta$ \\
\hline Patient age & & 0.001 & 0.003 & 0.023 \\
\hline Number of drugs & & $<0.001$ & 0.017 & -0.057 \\
\hline \multirow{8}{*}{$\begin{array}{l}\text { Prescribed } \\
\text { compound }\end{array}$} & & $<0.001$ & $<0.001$ & \\
\hline & $\begin{array}{l}\text { Analgesics and } \\
\text { non-steroidal anti- } \\
\text { inflammatory drugs }\end{array}$ & & 0.002 & 2.481 \\
\hline & Anti-infectives & & 0.623 & -0.225 \\
\hline & $\begin{array}{l}\text { Cardiovascular } \\
\text { drugs }\end{array}$ & & Reference & \\
\hline & Hormones & & 0.659 & -0.204 \\
\hline & $\begin{array}{l}\text { Immunomodulating } \\
\text { and antineoplastic } \\
\text { drugs }\end{array}$ & & 0.002 & 2.541 \\
\hline & Psychotropic drugs & & 0.003 & 1.463 \\
\hline & Miscellaneous & & 0.015 & 1.15 \\
\hline \multirow[t]{6}{*}{ Reason for the alert } & & $<0.001$ & $<0.001$ & \\
\hline & $\begin{array}{l}\text { Prescribed daily } \\
\text { dose }>\text { iMRTD } \\
\text { value }\end{array}$ & & Reference & \\
\hline & $\begin{array}{l}\text { Loading dose not } \\
\text { specified }\end{array}$ & & 0.566 & 0.229 \\
\hline & $\begin{array}{l}\text { Plasma } \\
\text { concentration in } \\
\text { excess of } \\
\text { therapeutic levels }\end{array}$ & & $<0.001$ & -3.35 \\
\hline & $\begin{array}{l}\text { No dosage } \\
\text { adjustment to renal } \\
\text { function }\end{array}$ & & 0.98 & 0.005 \\
\hline & $\begin{array}{l}\text { Duplicate } \\
\text { prescription }\end{array}$ & & $<0.001$ & 2.05 \\
\hline
\end{tabular}

Table includes all predictors with statistically significant impact on alert adherence. iMRTD, MRTD ${ }_{\text {final }}$ was individualised to renal function.

dosage regimens or mandatory definition of a dosage regimen to proceed in the prescription.

The present study has certain limitations. The CDSS was integrated in the CPOE of a tertiary care hospital; however, the prescription platform was frequently used for patients with transplants or diabetes, which resulted in a younger patient population than expected in standard internal medicine wards. Hence, patient selection and the large number of prescriptions without dosage regimens precluding decision support may have biased the outcome. Moreover, we focussed on excessive dosages potentially increasing the risk of adverse drug reactions, and warnings were only triggered when dosages exceeded iMRTD by $\geq 30 \%$. Therefore, neither adherence to therapeutic doses nor potential underdosing was assessed. While the calculation of iMRTD considered a number of regulatory requirements and relevant modulators of drug elimination, not all conceivable modifiers of drug exposure (eg, genetic polymorphisms, multiple interacting comedication) were included. Given the abundance of clearance-modifying drug interactions, quantitative information on the impact of drug combinations is needed to further personalise risk identification and alerts. ${ }^{29}$ Finally, the present study focussed on the improvement of prescribing quality as a surrogate for drug-associated risk and effectiveness but did not evaluate patient outcome. However, error-free drug prescription is a precondition for pharmacotherapeutic success and safety. Conversely, prescription of excessive doses is a well-documented risk factor for the occurrence of adverse events. ${ }^{30}$

\section{CONCLUSION}

Implementation of a highly specific, algorithm-based CDSS reduces prescriptions of excessive doses by $20 \%$ and substantially improves prescribing quality. However, there are certain groups of drugs that are not suitable for dose alerting by a CDSS.

Funding The work was supported in part by the Chamber of Pharmacists, Baden-Wuerttemberg, Germany. The funding source was not involved in study design, collection, analysis, interpretation of data or in writing the report and submitting it for publication.

\section{Competing interests None.}

Ethics approval This study was conducted with the approval of the Ethics Committee of the Medical Faculty of the University of Heidelberg.

Contributors HMS, SPWS, IWS, TBe and WEH designed the study protocol. HMS, MGP, CS, SPWS, JK, IWS, TBe and WEH were involved in developing the knowledgebase and the CDS system. HMS and SPWS conducted the study, HMS, SPWS, TBr, IWS and WEH carried out analysis and interpretation of the data. TBe, JK and WEH raised funding and supervised the whole study. HMS prepared the first draft of the manuscript. All authors critically revised the manuscript. HMS and WEH had full access to all of the data in the study and take responsibility for the integrity of the data and the accuracy of the data analysis.

Provenance and peer review Not commissioned; externally peer reviewed.

\section{REFERENCES}

1. Lesar TS, Lomaestro BM, Pohl H. Medication-prescribing errors in a teaching hospital. A 9-year experience. Arch Intern Med 1997;157:1569-76.

2. Bates DW, Cullen DJ, Laird N, et al. Incidence of adverse drug events and potential adverse drug events. Implications for prevention. ADE prevention study group. JAMA 1995;274:29-34.

3. Winterstein AG, Johns TE, Rosenberg El, et al. Nature and causes of clinically significant medication errors in a tertiary care hospital. Am J Health Syst Pharm 2004;61:1908-16.

4. Lesar TS. Tenfold medication dose prescribing errors. Ann Pharmacother 2002:36:1833-39.

5. Rodighiero V. Effects of liver disease on pharmacokinetics. An update. Clin Pharmacokinet 1999;37:399-431.

6. Munar MY, Singh H. Drug dosing adjustments in patients with chronic kidney disease. Am Fam Physician 2007;75:1487-96

7. Boulle A, Cutsem GV, Cohen K, et al. Outcomes of nevirapine- and efavirenz-based antiretroviral therapy when coadministered with rifampicin-based antitubercular therapy. JAMA 2008; 300:530-9.

8. Vuyk J. Pharmacodynamics in the elderly. Best Pract Res Clin Anaesthesiol 2003:17:207-18.

9. Kirchheiner J, Seeringer A. Clinical implications of pharmacogenetics of cytochrome P450 drug metabolizing enzymes. Biochim Biophys Acta 2007; 1770:489-94.

10. Kaushal R, Shojania KG, Bates DW. Effects of computerized physician order entry and clinical decision support systems on medication safety. A systematic review. Arch Intern Med 2003;163:1409-16.

11. Mitra R, Marciello MA, Brain C, et al. Efficacy of computer-aided dosing of warfarin among patients in a rehabilitation hospital. Am J Phys Med Rehabil 2005;84:423-7.

12. Lenert LA, Klostermann H, Coleman RW, et al. Practical computer-assisted dosing for aminoglycoside antibiotics. Antimicrob Agents Chemother 1992;36:1230-5

13. Casner PR, Reilly R, Ho H. A randomized controlled trial of computerized pharmacokinetic theophylline dosing versus empiric physician dosing. Clin Pharmacol Ther 1993;53:684-90.

14. Peterson JF, Kuperman GJ, Shek C, et al. Guided prescription of psychotropic medications for geriatric inpatients. Arch Intern Med 2005;165 802-7.

15. Kirk RC, Goh DL, Packia J, et al. Computer calculated dose in paediatric prescribing Drug Saf 2005:28:817-24.

16. Chertow GM, Lee J, Kuperman GJ, et al. Guided medication dosing for inpatients with renal insufficiency. JAMA 2001;286:2839-44.

17. Seidling HM, Barmawi AA, Kaltschmidt J, et al. Detection and prevention of prescriptions with excessive doses in electronic prescribing systems. Eur J Clin Pharmacol 2007;63:1185-92.

18. A guideline on summary of products characteristics [online]. 2009. http//:ec europa.eu/enterprise/pharmaceuticals/eudralex/vol-2/c/smpc guideline rev2.pdf (accessed Jan 2009).

19. Health Canada. Bioequivalence requirements: critical dose drugs [online]. 2006 http://www.hc-sc.gc.ca/dhp-mps/prodpharma/applic-demande/guide-ld/bio/ critical_dose_critique-eng.php. (accessed Jan 2009).

20. Martin-Fack̄lam M, Rengelshausen J, Tayrouz $Y$, et al. Dose individualisation in patients with renal insufficiency: does drug labelling support optimal management? Eur J Clin Pharmacol 2005;60:807-11. 
21. Dettli L. The kidney in pre-clinical and clinical pharmacokinetics. Jpn J Clin Pharmacol Ther 1983;15:241-54.

22. EMEA. Note for guidance on the investigation of bioavailability and bioequivalence of medicinal products [online]. 2000. http://www.emea.europa.eu/pdfs/human/ qwp/140198en.pdf (accessed Nov 2008).

23. Koppel R, Metlay JP, Cohen A, et al. Role of computerized physician order entry systems in facilitating medication errors. JAMA 2005;293:1197-203.

24. Taylor LK, Tamblyn R. Reasons for physician non-adherence to electronic drug alerts. Stud Health Technol Inform 2004:107(Pt 2):1101-5.

25. Nightingale PG, Adu D, Richards NT, et al. Implementation of rules based computerised bedside prescribing and administration: intervention study. BMJ 2000:320:750-3.
26. Kawamoto K, Houlihan CA, Balas EA, et al. Improving clinical practice using clinical decision support systems: a systematic review of trials to identify features critical to success. BMJ 2005; 330:765.

27. van der Sijs H, Aarts J, Vulto A, et al. Overriding of drug safety alerts in computerized physician order entry. J Am Med Inform Assoc 2006;13:138-47.

28. Leendertse AJ, Egberts AC, Stoker LJ, et al. HARM study group. Frequency of and risk factors for preventable medication-related hospital admissions in the Netherlands. Arch Intern Med 2008;168:1890-6.

29. Seidling HM, Storch $\mathrm{CH}$, Bertsche T, et al. Successful strategy to improve specificity of electronic statin-drug interaction alerts. Eur J Clin Pharmacol 2009;65:1149-57.

30. Shah RR. Mechanistic basis of adverse drug reactions: the perils of inappropriate dose schedules. Expert Opin Drug Saf 2005:4:103-28. 